\title{
A Comprehensive Review on the Related Models in Magneto-Rheological Automobile Suspension System
}

\author{
S. F. Yaakub ${ }^{1,2}$, S. H. Yahaya ${ }^{1, *}$, F. Ahmad ${ }^{3}$, M.S. Salleh ${ }^{1}$, A.R.M. Warikh ${ }^{1}$ \\ ${ }^{1}$ Fakulti Kejuruteraan Pembuatan, Universiti Teknikal Melaka, 76100, Malaysia. \\ ${ }^{2}$ Jabatan Pendidikan Politeknik dan Kolej Komuniti, 62100, Putrajaya, Malaysia. \\ ${ }^{3}$ Fakulti Kejuruteraan Mekanikal, Universiti Teknikal Melaka, 76100, Malaysia. \\ *Corresponding author's (ORCID: 0000-0003-0525-6243)
}

\begin{abstract}
In this article, the Magneto-Rheological (MR) automobile suspension is thoroughly reviewed. MR suspension has a smart behaviour of the fluid and it is preferred in many industries. The paper reviews the different model which was developed to represent the behaviour of MR suspension in automobile systems. This paper also presents the advantages, drawback and parameter estimation error for all proposed models. The conclusion of the intelligent model used to represent the behaviour of the MR automobile suspension systems also described.
\end{abstract}

Keywords: Automobile suspension, MR damper, Parameter model, MR behavior, Semi-active.

\section{INTRODUCTION}

Suspension is a term given to the system of springs, shock absorbers and linkages that connects a vehicle to its wheels. These suspension components support the vehicle and transmits its weight to the wheels. Suspension systems serve a dual purpose which is contributing to the car's road holding/handling and braking for good active safety and driving pleasure, and keeping vehicle occupants comfortable and reasonably well isolated from road noise, bumps, vibrations, and others. The perfect automobile suspension system can absorb road shocks that produced by the vehicle rapidly and return it to the normal position slowly while maintaining optimal contact between the tire and the surface of the road [1]. Reyat [2] mentioned that it is essential for the suspension to keep the road wheel in contact with the road surface as much as possible, because all the forces acting on the vehicle do so through the contact patches the tires. The suspension also serves several secondary purposes such as alters the positions of the wheels to increase the traction when the load transfers during cornering. The others secondary purpose is to resist change in wheel positions during cornering to decrease traction and helps the metal brackets, wiring harnesses and structural components throughout the vehicle last longer by cushioning against road shocks [2]. Suspension working by compression where when a wheel rides over the bumps, the suspension compresses to absorb the energy of the jolt instead of transmitting it to the frame and known as jounce. The opposite of jounce is rebounded which occurs when the force of the compressing removed and the suspension extends.
The complete cycle of the suspension jounce and rebound or compression and extension known as bounce.

Ox-drawn was an early form of suspension. This model had the platform swing on iron chains attached to the wheeled frame of the carriage. The suspension model was invented in $1500 \mathrm{~s}$ which the body of the carriage was suspended from the frame by chains or by the leather straps. The suspension gives passengers compartment sway instead of bumping on the rough road surfaces. In the $1600 \mathrm{~s}$, carriage makers began mounting the suspensions straps on metal spring that attached to the frame. However, this type of suspension was just suitable for slow speed systems, and the suspension design was not suitable to the higher speed combustion engine. Christian Huyghens, describes the first internal combustion engine with single cylinder and single piston engine [3]. This idea converts horse drawn carriage into horseless carriage. The dawn of the actual history of the automobile was in 1769 when Captain Nicholas Cugnot from France built the actual-propelled road vehicles. It was a three wheeled carriage propelled by steam engine. Its engine drives the front single wheel and the boiler of the engine was projecting towards front of the vehicles. This carriage had to stop every hundred feet to develop the steam. Therefore, in 1801s, Richard Trevithick built England's full-sized steam carriage. The steam vehicles had the disadvantages which was a long starting period and the limited fuel supply [3].

This suspension system remained the basis until the turn of the 19th century [3]. The first vehicle pattern with a spring was introduced by Obadiah Elliott which had two durable steel leaf springs on each side of the wheels and the body of the carriage was fixed directly to the springs which were attached to the axles. The springs were developed in a variety of shapes, types, sizes, and capacities. These were often made of low carbon steel and usually took the form of multiple layer leaf spring. In 1901, Mors of Paris first fitted an automobile with shock absorbers. Coil spring first appeared on vehicle production in 1906 in the Brush Runabout which was made by the Brush Motor Company. In the year of 1932, the independent front suspension became more common in popular cars. Triumph Mayflower introduced the combined of the coil spring and damper unit in 1948 and in 1950 Ford adopted the McPherson strut independent front suspension.

The key function of the car suspension is to deliver a smooth ride and maintain an excellent control. It does this by maintaining the tyre position to an optimum angle that 
eventually maximizes traction control, steering control, braking, and even the acceleration. When acceleration transforms into force or when a vehicle hit the bump, the vertical energy travels through the frame of the vehicle. This forceful energy is trapped by the car suspension system and reduces the tyre friction, eventually preventing the car from jumping. The ride is enhanced by method for the decrease of the body acceleration which is caused by the car body when road disturbances from smooth road and real road roughness. Despite the fact that car suspensions come in variety of configurations, the basic elements are springs and shock absorber. In the engineering term, the suspension system can be categorized into passive, active and semi-active suspension system according to external power input to the system and/or a control bandwidth [4].

A passive suspension system is an ordinary suspension system consists a non-controlled spring and shocking-absorbing damper as Fig. 1. The commercial vehicles today use passive suspension system to control the dynamics of a vehicle's vertical motion as well as pitch and roll. Passive indicates that the suspension elements cannot supply energy to the suspension system. The passive suspension system controls the motion of the body and wheel by limiting their relative velocities to a rate that gives the desired ride characteristics. The good automotive suspension system can absorb road shocks rapidly and could return to its normal position slowly while maintaining optimal tire to road contact $[1,5,6]$. However, this condition is difficult if passive automobile suspension system is used. Passive automobile suspension systems will produce too much movement if the soft spring is being used and a hard spring causes passenger discomfort due to the road irregularities. The passive automobile suspension system incorporates the hydraulic damper and mechanical spring. The disadvantage of the passive suspension systems is the design that only achieves certain condition. The characteristics of this suspension system also fixed and cannot be adjusted by any mechanical part. Yahaya [7] stated that the problem of passive suspension systems is evident when the vehicle travels at the low speed on a rough road or at the high speed in a straight line, where it will be perceived as a harsh road. Then, if the suspension is designed lightly damped, it will give more comfortable ride. Unfortunately, this design will reduce the stability of the vehicle in making turn and lane changing.

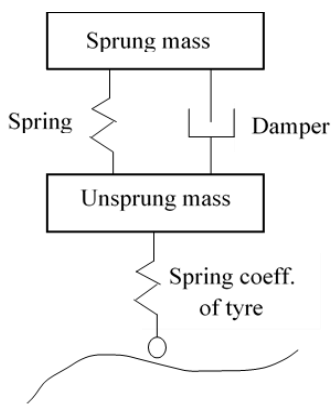

Fig. 1. A Passive Suspension System

Active suspension was produced to improve the passive suspension system. A novel study by Yahaya [8] revealed that active suspension differ from the conventional passive suspension to get the energy into the suspension system. This automobile suspension system controls the vertical movement of the wheels relative to the chassis or vehicle body onboard system, different with the passive suspension which is determined by the road surface. An active suspension is one in which passive components are augmented by actuators that supply additional force as Fig. 2. Active suspensions differ from the conventional passive suspensions in their ability to inject energy into the system, as well as store and dissipate it.

The active suspension is divided into two categories: the lowbandwidth or soft active suspension and the high-bandwidth or stiff active suspension. Therefore, such type of suspension can only improve the ride comfort. [5,9]. Active suspension system uses skyhook theory to let the car maintain a stable posture and unaffected by the road conditions. Since the actual skyhook is impractical, therefore the real active suspension system is based on actuator operations. The first active suspension system was introduced by using separate actuator which can exert an independent force on the suspension to improve the riding characteristics. Martin and his co-workers [10] stated that the active suspension is high cost and complex in order to develop power electronics, permanent magnet materials, and microelectronic systems justifies analysis of the possibility of implementing electromagnetic actuators in order to improve the performance of automobile suspension systems. The active automobile suspension also needs frequent maintenance in some implementations and maintenance can require special tools, and some problems can be difficult to be diagnosed. In this regard, active elements are capable of inducing arbitrary forces to provide the best performance; however, they have higher energy requirements and a complex mechanical implementation [11]. On the other hand, semi-active dampers allow modifying the dynamical properties of the suspension system with less energy consumption and mechanical complexity. The result is that semi-active system is less expensive, yielding a better level of performance-versus-cost ratio.

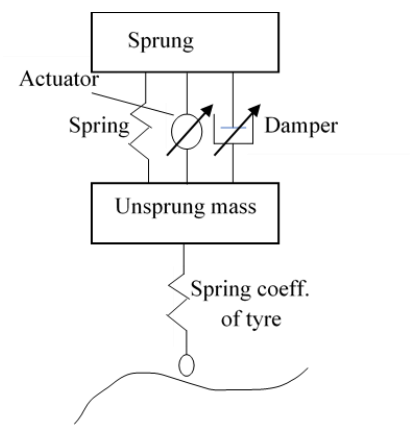

Fig. 2. An Active Suspension System

The semi-active suspension has the same elements as passive suspension system but the damper has two or more selectable damping rate as shown in Fig. 3. Semi-active system can only change the viscous damping coefficient of the shock absorber, and does not add energy to the suspension system. The semiactive suspension system also has an ability to reduce acceleration of sprung mass continuously. This ability will improve the tire grip with the road surface, thus, brake, traction control and vehicle maneuverability can be considerably improved [12]. The damper or spring in semi-active system is intercedied by the force actuator which has its own task to add 
the energy from the suspension system. The force actuator is controlled by various types of controller determined by the designer. The dynamic behavior of the system in nature can be observed by neglecting of the effect of force and damping elements [13].

There are few studies have been conducted to determine the semi-active suspension system to provide better result compare to the passive suspension systems. Ankita et al. [9] identified that traditionally or passive automotive suspension systems are designed with three criteria which are load capacity, passengers' comfort and road handling. The semi-active suspension system with its controller has good performance in vibration suppression on various operation conditions [14]. For the better comfort ride and vehicle stability, it is important to use the correct control strategy. However, surprisingly, a few researchers have studied in this field to find the optimization design in improving the ride comfort. Griffin [15] has performed a detailed experimental work to determine the effects of road excitation on ride comfort. Several methods are also developed in the field such as rotating square evolutionary operation (ROVOP), gradient based method, genetic algorithm and sequential search method in order to determine the ride comfort. Shirahatti et al. [16] has used Genetic Algorithm to find out the minimum acceleration and road holding and where the results were compared with the Simulink model. From Zayed et al. [17] studied conclude that the comparison between experimental result for passive system and semi-active system showed the MR damper improve the stability of the system. Semi-active suspension also won the favors of vehicle manufactures because it consists the advantageous such as high strength, good controllability, wide dynamic range, fast response rate, low energy consumption and simple structure. Magneto-rheological (MR) damper is an intelligent damper, which is used as automobile suspension for vibration semiactive control [18].

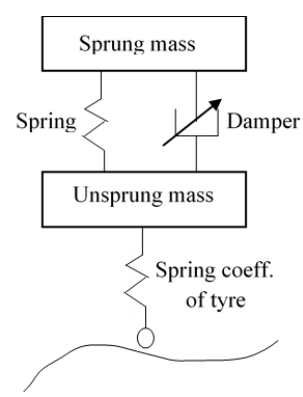

Fig. 3. Semi-Active Automobile Suspension System

Some literature studies have investigated about MR suspension in automobile systems. To improve the comfort and stability of the automobile, MR has been dispersed into conventional suspension system and its performance has been acknowledged by many researchers. However, there are some discrepancies in the reported findings especially in the behaviour of the MR suspension, the best model used to optimize the MR damper, and others. Therefore, in the present paper, we attempt to review thoroughly the model for MR damper in automobile systems that have been published previously. To the best of authors' knowledge, there is no comprehensive literature on the subject.

This paper is organized as follows: The introduction about suspension, passive, active and semi-active automobile suspension systems are studied in Section 1. The MagnetoRheological automobile suspension systems are established in Section 2. Section 3 about the model for Magneto-Rheological automobile suspension systems. Finally, this study is concluded in Section 4.

\section{MAGNETO-RHEOLOGICAL AUTOMOBILE SUSPENSION SYSTEM}

Ankita et al. [9] also stated the semi-active using Magnetorheological (MR) damper offers a better control performance than passive system. MR damper becomes the most promising vibration controller in the intelligent suspension presently. The advantageous of high strength, good controllability, wide dynamic range, fast response rate, low energy consumption and simple structure make MR damper wins the favour of vehicle manufactures [19]. Now, American LORD and Delphi companies have developed automobile suspension MR damper and it has been used in Cardilac and Audi cars. Chinese car manufactures also give good attention to this intelligent suspension and take an active part in research on the technology and production. Moreover, with the increasing requirement of vehicle ride comfortable and safety, intelligent suspension will be widely adopted in normal cars and engineering automobile. Consequently, MR damper will bring broad market to automobile suspension industries. Ambhore et al. [20] also mentioned that MR damper is an intelligent damper which can used as automobile suspension for vibration control. MR damper have the main advantages such as need very less control power, has simple construction, quick response to control signal and very few moving parts.

The semi-active devices use controllable fluids which have the essential characteristic that able to reversibly change freeflowing and linear viscous fluid to a semi-solid [21]. Rheological damper's work concept depends on how the magneto-rheological fluid works. Each of the magnetorheological fluids (MR fluids), which have been discovered by Jacob Rabinow in the 1940's [22], known as a multi-functional fluid for its property of getting magnetized. MR fluids represent a class of smart materials that respond to an applied electric or magnetic field with a dramatic change in rheological behaviour [20]. MR fluid such as silicon or mineral oil that contains micron-sized magnetically polarized particles and when the fluid magnetic field is un-activated, the oil behaves as ordinary oil. When the current passes through magnetic coil then the magnetic field is produced. MR fluid is exposed to this field when micron-size iron particles that are dispersed throughout the fluid align themselves along magnetic flux lines as shown in Fig. 4 and 5. Phule [23] studies mentioned that MR fluids particles have improved stability and dispersibility were prepared utilizing both iron and ferrite particles. The stability can be improved by using nano-scale additives. The flow characteristics of this non-Newtonain fluid change within a millisecond to achieve a specific damping constant to minimize the force which translates to the vehicle body and the passenger 
seat [24]. The magnetic field can be controlled according to the system excitation. Magnetic circuit parameter and structure parameter act or react to each other and usually they are needed to be calibrated repeatedly [18]. The rheological behaviour changed whenever the strength of magnetic field changed [25]. The MR fluid damper is also a device that appears to be particularly promising for suspension protection. The MR fluid is used to produce a controllable damping force. The MR fluid has higher magnitude of yield stress [26]. MR fluid also is a kind of smart material whose viscosity can be changed using an external magnetic field. Moreover, MR fluid fluided in semiactive suspension system for giving the actuators controlled the produced vibration effectively. MR fluid damper is a semiactive control device applied the MR fluid to produce the controllable damping force [27]. The design of the MR fluid is mainly about the application of MR fluid damper. To get the performance of the design, combination of the damper controllable damping force and damping force adjustable range are used [28]. In previous study, MR fluid also applied in various engineering devices such as dampers, clutches, brakes and valves [29].

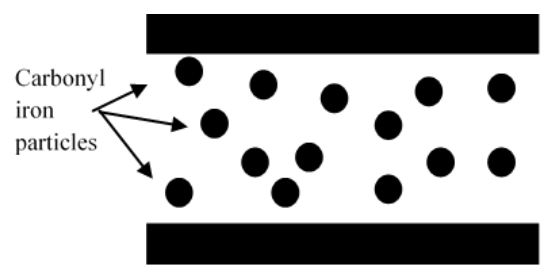

Fig.4. Off-State MR Particle

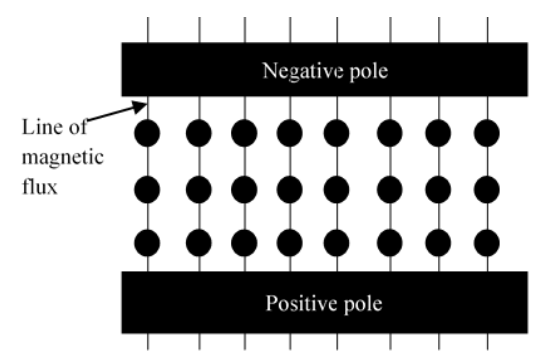

Fig. 5. Aligning in Applied Magnetic Field

\section{MODEL OF MAGNETO-RHEOLOGICAL AUTOMOBILE SUSPENSION SYSTEM}

The damping force is generated by the MR damper cannot be controlled directly because it depends on the input current (voltage) to the MR damper and the relative velocity and displacement between the piston and the damper shell, among which only the input current (voltage) can be controlled [30]. Therefore, the designation of the damper controller remains as an important unresolved issue in the application of a Magnetorheological damper. Hence, force tracking control of the MR damper model to the corresponding desired control force can be achieved by having an appropriate damper controller. The experiments are usually performed on a commercially available MR damper. The reported models of hysteretic systems have employed different techniques in formulate the damping force function. Few types of model were developed to present the behaviour of the MR damper such as Bingham model, Simple Bouc-Wen model, Modified BoucWen model, Hyperbolic Tangent Function model, Nonlinear Biviscous model and The Finite Element model.

\section{III.I. Bingham Model}

Bingham model is the earliest, simplest and most commonly used model for predicting the response of magneto rheological damping system. The Bingham model is simple, clear and easy to understand the relationship between the damping force displacement of the MR damper. However, Bingham model cannot describe the damping force velocity nonlinearity, so that it is only suitable to analyse the reaction and not suitable to control analysis [11]. Bingham model describe as

$$
F=c_{0} \dot{x}+f_{c} \operatorname{sgn}(\dot{x})+f_{0}
$$

with frictional force, $f_{c}$ represents yield of damper, $f_{0}$ is a storage energy, $c_{0}$ is damping coefficient, $\dot{x}$ is the input velocity and $F$ is the force from MR damper.

Ankita et al. [9] studies stated that the Bingham model is a simple model because only two parameters are needed to characterize the MR damper behavior and makes the analysis become simple. The signum function appearing in the Bingham model results in a non-smooth dynamic behavior [31]. Signum function returns an integer indicates the sign of a number which the number argument determines the return value of the sign function. Semi-active suspension system based on Bingham model have $93.9 \%$ and $63.70 \%$ percentage of fluctuation in maximum sprung mass acceleration for Step and Half Sine respectively from passive suspension system. So, it shows that semi-active suspension system gives lower value of maximum sprung mass acceleration for Step and Half Sine road excitation. There is a new approach of controlling the response of a quarter car vehicle travelling on rough roads with semi active MR damper suspension and MR damper performance is founded to be better compared to the conventional passive damper system $[9,32]$.

In Khusyaie et al. [25] studied, the error for parameter estimation is 3.8096 from Bingham model compared to other models determine the most suitable model to represent the behavior of the MR damper. Then, force velocity response and the temporal variation of the force shows that the behavior of the damper is not captured mentioned by Spencer et al. [21]. In particular, Bingham model does not exhibit the nonlinear force velocity response. It can be observed in the data when the acceleration and velocity have opposite signs and the magnitude of the velocities are small. Therefore, Bouc-Wen model that have been used extensively introduced for modelling the systems [21].

\section{III.II. Bouc-Wen Model}

Bouc-Wen model proposed by Wen in 1997 as shown in Fig. 6 [11]. The Bouc-Wen model contains a viscous damper, a spring and a hysteretic element $[33,34]$. This model also can describe the relation between displacement and force of MR damper [35-39]. The characteristic of this model can fit the test result which has a smooth transition, easy on numerical calculation, 
have a strong versatility and can reflect in all kind of hyteresis systems [28].

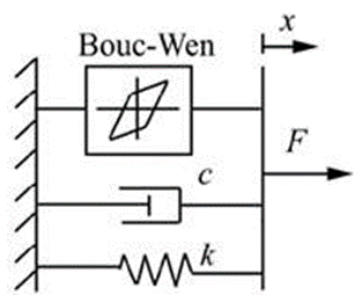

Fig. 6. Bouc-Wen Model [11]

The damping force for Bouc-Wen model is

$$
\begin{array}{r}
F=\propto z+c_{0} \dot{x}+k_{0}\left(x-x_{0}\right) \\
\dot{z}=\gamma|\dot{x}| z\left(|z|^{n-1}\right)-\beta \dot{x}|z|^{n}+A \dot{x}
\end{array}
$$

$c_{0}$ is damping coefficient, $k_{0}$ is spring stiffness, $x$ is displacement of the damper piston rod, $\propto$ represents the coefficients determined by the control system and the magneto rheological fluid, $z$ is evolutional variable of the damper and $A, \beta, \gamma$ and $n$ are Bouc-Wen parameters to control the shape of the hysteresis loop [40].

Spencer et al. [21] mentioned that the Bouc-Wen model predicts the force displacement behavior of the damper well, and it forces velocity behavior closer than the experimental data. However, it is similar with Bingham model, nonlinear force velocity response for the Bouc-Wen model does not roll-off in the region where the acceleration and velocity have opposite signs and magnitude of the velocities are small. For Bouc-Wen model, the parameter estimation error for this model is 1.9245 mentioned by Khusyaie et al. [25]. Bouc-Wen model also still does not totally represent MR damper because it cannot fit damping force velocity with nonlinear characteristics [41]. To be better results, the modified version of the systems is proposed.

\section{III.III. Modified Bouc-Wen Model}

In the model proposed by Spencer [21] as a Fig. 7, other parameters have to be included to get more tidy results $[37,42-$ 46]. For Modified Bouc-Wen model, the accuracy of estimation of MR damper behavior is modified compared to Bouc-wen model. The internal displacement of damper is $y, k_{1}$ is accumulator stiffness of the damper, $x_{0}$ is initial displacement and $c$ is damping coefficients. This model represents as follows:

$$
\begin{array}{r}
F=c_{1} y+k_{1}\left(x-x_{0}\right) \\
\dot{y}=\frac{1}{c_{0}+c_{1}}\left[\propto z+c_{0} \dot{x}+k_{0}\left(x-x_{0}\right)\right] \\
\dot{z}=-\gamma|\dot{x}-\dot{y}|\left(|z|^{n-1}\right) z-\beta(\dot{x}-\dot{y})|z|^{n}+A(\dot{x}-\dot{y})
\end{array}
$$

Viswanathan et al. [26] stated that the performance of the MR Fluid damper obtained by using the Modified Bouc-Wen model is better as compared to the Bouc-Wen model in term of time settlement. The time settlement is needed for the suspension system for the Modified Bouc-Wen model back to its origin position is shortest compared to the Bouc-Wen model between the values of voltage of $0 \mathrm{~V}, 1 \mathrm{~V}$ and $2 \mathrm{~V}$. It can be summarized that the car system with Modified Bouc-Wen model is able to attain its stability within short period of time.
Modified Bouc-Wen model predicts the behavior of the damper very well in all regions, including in the region where the acceleration and velocity have opposite sign and the magnitude of the velocities are small $[21,47]$. The parameter estimation error for this model is 1.3770 for input current 0 to 1 Ampere that applied on the damper [25].

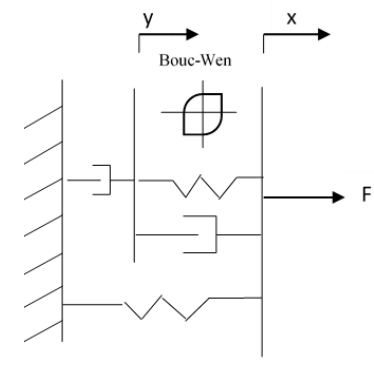

Fig. 7. Modified Bouc-Wen Model

\section{III.IV. Nonlinear Biviscous Model}

Nonlinear Biviscous model, MR fluids assumes as plastic in both pre-yield and post-yield region [48-51]. The model can present as

$$
\begin{array}{r}
F=\left\{\begin{array}{r}
c_{\text {post }} \dot{x}+F_{y}, \quad \dot{x} \geq \dot{x_{y}} \\
c_{\text {pre }} \dot{x}, \quad-\dot{x}_{y} \geq x \geq \dot{x_{y}} \\
c_{\text {post }} \dot{x}-F_{y}, \quad \dot{x} \leq-\dot{x_{y}}
\end{array}\right. \\
\dot{x}=\frac{F_{y}}{c_{\text {pre }}-c_{\text {post }}} c_{\text {pre }}
\end{array}
$$

with $c_{\text {pre }}$ and $c_{\text {post }}$ are the damping coefficient, $F_{y}$ is the yield force and the $\dot{x}_{y}$ is the yield velocity.

This model is compared with the experimental result by Khusyaie et al. [25] using LORD RD-8041-1 damper. The force applied on the damper is in downward motion and the experiment is repeated for a few times with the different value of current input. Nonlinear least square method is used for parameter estimation. The error of the parameter estimation is 3.8052 for this model. The disadvantage of this model is disability to perform well with varying input excitation current [25]. An enhanced model in order to better represent the preyield hysteresis's represented by the non-linear hysteretic biviscous model $[49,50,52]$. Stanway et al. [28] proposed that the relationship between the four parameters and the current could be described with second or fourth order polynomials. But this model cannot describe accurately the $F(t)$ if the current value change, because the characteristic of the parameters must be evaluated. However, further works by $[53,54]$ have brought forward a parameter for bi-viscous model that can describes the motion of the fluid considering an additional nonlinear function (quasi-steady velocity), the control signal of the damper, the fluid compressibility and inertia and the piston's mass. This model proposes hyperbolic tangent functions to solve the current effect on $F_{y i e l d}, c_{\text {pre }}$, and $c_{\text {post }}$ parameters. 


\section{III.V. Hyperbolic Tangent Function}

This model is better from the perspective of controller design, parameter identification and implementation [55]. The hyperbolic tangent function model can be described as

$$
\begin{array}{r}
F=\propto z+c_{0} \dot{x}+k_{0} x+f_{0} \\
z=\tanh [\beta \dot{x}+\delta \operatorname{sign}(x)]
\end{array}
$$

where $k_{0}$ is spring coefficient, $c_{0}$ is damper coefficient, $f_{0}$ as offset force, $\propto$ is the scale factor of the hysteresis, $z$ is the hysteretic variable, $\beta$ is the scale factor in controlling the hysteretic slope and $\delta$ is the scale factor in controlling the width of the hysteresis loop.

Hyperbolic Tangent Function model showed that the relationship between parameter value and input current mostly is nonlinear [25]. This is due to the nonlinear behavior of MR damper itself. From the study also mentioned that the parameter value can be estimated directly from the estimated equation within 0 to $1 \mathrm{~A}$ of input current and the estimation error for the parameter is 3.3688. The hyperbolic tangent model is established to characterize the performance of MR damper that is developed for a vehicle suspension system. The semi-active suspension system displayed more effectively in vibration when the MR damper is combined with corresponding control algorithms [56].

\section{III.VI. The Finite Element Model}

The finite element model is the simulation of the magnetic flux density on the area where MR fluid is stored. The flux lines concentration increases as the distance between one flux lines to its adjacent becomes closer. The average magnitude of the magnetic flux density of a particular applied current can be calculated by dividing the summation of the highest value and the lowest value generated in the solution by two [57]. The expression of the equation for this model is in the form of fourth-order polynomial.

$$
\begin{gathered}
\tau_{y}=6.298 B_{f}^{4}-25.824 B_{f}^{3}+26.639 B_{f}^{2} \\
-0.43 B_{f}
\end{gathered}
$$

The equation expresses the magnetic flux density as a function of the fluid shear stress. The finite element modelling results provide evidence that the semi-active damper works well in exploiting the unique properties of the MR fluid. The MR semiactive damper also improves the ride comfort by decreasing the acceleration of the sprung mass compare to the passive damper [57]. The summary of previous research on MR suspension model in automobile systems is tabulated in Table 1.

\begin{tabular}{|c|c|c|}
\hline & $\begin{array}{l}\text { 4. The hysteresis behaviour not } \\
\text { considered. } \\
\text { 5. The parameter estimation error is } \\
\text { 3.8096 }\end{array}$ & [24] \\
\hline Bouc-Wen & $\begin{array}{l}\text { 1.Predict the force displacement } \\
\text { behaviour well. } \\
\text { 2. Has a smooth transition, strong } \\
\text { versatility and strong versatility. } \\
\text { 3. Can reflect in all kind of hyteresis } \\
\text { systems. } \\
\text { 4. The parameter estimation error is } \\
1.9245 \\
\text { 5.Many parameters must be } \\
\text { considered. }\end{array}$ & $\begin{array}{c}{[39]} \\
{[25]} \\
{[19,25]} \\
{[24]} \\
{[50]}\end{array}$ \\
\hline $\begin{array}{l}\text { Modified } \\
\text { Bouc-Wen }\end{array}$ & $\begin{array}{l}\text { 1. Modified Bouc-Wen model is } \\
\text { better as compared to the Bouc- } \\
\text { Wen model in time settlement. } \\
\text { 2. Able to attain its stability within } \\
\text { short period of time. } \\
\text { 3. Predicts the behavoiur of the } \\
\text { damper very well in all } \\
\text { regions. } \\
\text { 4. Acceleration and velocity have } \\
\text { opposite signs. } \\
\text { 5. The parameter estimation error is } \\
\text { 1.3770. } \\
\text { 6. Magnitude of the velocities is small. }\end{array}$ & $\begin{array}{c}{[33]} \\
{[24]} \\
{[17,39} \\
42]\end{array}$ \\
\hline $\begin{array}{l}\text { Hyperbolic } \\
\text { Tangent } \\
\text { Function }\end{array}$ & $\begin{array}{l}\text { 1. Better in controller design, } \\
\text { parameter identification and } \\
\text { implementation. } \\
\text { 2. Relationship between parameter } \\
\text { value and input current is } \\
\text { nonlinear. } \\
\text { 3. Parameter value can be estimated } \\
\text { directly from the estimated } \\
\text { equation and the parameter } \\
\text { estimation error is } 3.3688 \text {. } \\
\end{array}$ & [32] \\
\hline $\begin{array}{l}\text { Nonlinear } \\
\text { Biviscous }\end{array}$ & $\begin{array}{l}\text { 1. Cannot describe accurately the } \mathrm{F}(\mathrm{t}) \\
\text { if the current value change. } \\
\text { 2. Disability to perform well with } \\
\text { varying input excitation current. } \\
\text { 3. The parameter estimation error is } \\
\text { 3.8052. }\end{array}$ & $\begin{array}{l}{[25]} \\
{[24]} \\
{[24]}\end{array}$ \\
\hline $\begin{array}{l}\text { Finite } \\
\text { Element }\end{array}$ & $\begin{array}{l}\text { 1. The flux lines increase as the } \\
\text { distance between one flux lines to } \\
\text { its adjacent become closer. } \\
\text { 2. Provide evidence that the semi- } \\
\text { active damper works well. } \\
\text { 3. MR semi-active damper also } \\
\text { improves the ride comfort compare } \\
\text { to passive damper. }\end{array}$ & $\begin{array}{l}{[57]} \\
{[57]}\end{array}$ \\
\hline \multicolumn{3}{|c|}{$\begin{array}{l}\text { Present Study: From all the studied model, Modified Bouc- } \\
\text { Wen model gives more advantages to the system. Therefore, for } \\
\text { the further work, MR damper will be added to the Modified } \\
\text { Bouc-Wen system as in Fig. } 8 \text {. The expected results for this } \\
\text { model are better in time settlement, stability in short period and } \\
\text { small magnitude of velocities compare to Modified Bouc-Wen } \\
\text { model. }\end{array}$} \\
\hline
\end{tabular}

Table 1: Summary of Previous Studies on MR Suspension Systems

\begin{tabular}{|l|l|c|}
\hline Model & Advantages and/or Drawback & Ref. \\
\hline Bingham & $\begin{array}{l}\text { 1. Easy to implement. } \\
\text { 2. Only two parameters are needed to } \\
\text { characterize the MR damper } \\
\text { behaviour. }\end{array}$ & {$[25]$} \\
& $\begin{array}{l}\text { 3.The MR damper performance is } \\
\text { better compared tothe conventional } \\
\text { passive damper system. }\end{array}$ & {$[6,41]$} \\
& & {$[39]$} \\
\hline
\end{tabular}




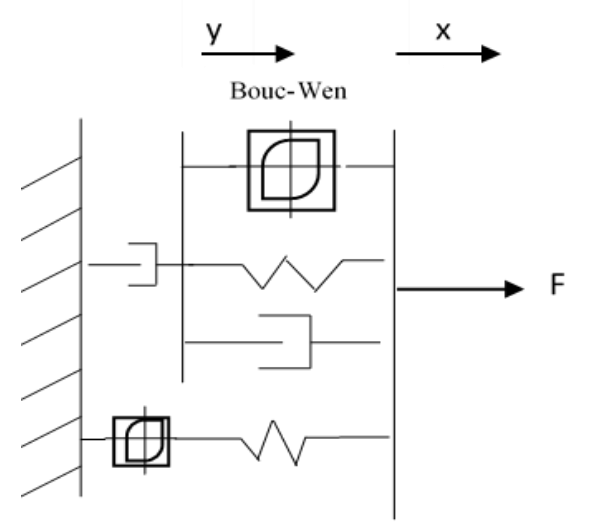

Fig. 8. Proposed Model

\section{CONCLUSION}

The MR suspension system for automobile system has been comprehensively reviewed. The effective of an MR damper depends on understanding its nonlinear hysteretic behavior under an applied magneticfield. Therefore, the mathematical models have to be developed for characterizing the intrinsic nonlinear behavior of the MR damper. The selection of optimal model is important in order to represent the real behaviour of the MR damper in mathematical form. This mathematical form will be used in controller design that will improve the performance of the MR damper. The selection of the model is based on the advantages from each model and paramter estimation error value. For the parameter estimation error, the lower error value gives the closer behaviour of the model with the real one. Modified Bouc-Wen model has the most advantages from other model and lowest parameter estimation error. Therefore, Modified Bouc-Wen model is the most suitable model to represent the behaviour of the MR damper and can be used to design controller or simulation study. The Modified Bouc-wen model also a successful model to describe a wide range of nonlinear hysteretic systems. For the future study, the proposed model can be tested with different features to expand its applications.

\section{REFERENCES}

[1] D. L. Trumper, W. J. Kim and M. E. Williams. Design and Analysis Framework for Linear Permanent-Magnet Machines. IEEE Transactions on Industry Applications. 1996;32(2): 371-379.

[2] H. S. Reyat. The Automobile, New Delhi, S. Chand \& Company LTD. 2004.

[3] M. Pelliciari, G. C. Marano, T. Cuoghi, B. Briseghella, D. Lavorato and M. Tarantino. Parameter Identification of Degrading and Pinched Hysteretic Systems Using a Modified Bouc-Wen Model. Journal of Structure and Infrastructure Engineering. 2018;14(12):1-13.

[4] N. M. Suaib. Modelling and Control of Active Suspension Using PISMC and SMC. Ph. D. Thesis, Universiti Teknologi Malaysia. 2008.
[5] R.E. Clark, D.S. Smith and P.H. Mellor. Design Optimization of Moving-Magnet Actuators for Recirocating Electro-Mechanical Systems Magnetics. IEEE Transactions on Magnetics. 1995;31(6):37463748 .

[6] Z.Q. Zhu and D. Howe. Magnet Design Considerations for Electrical Machines Equipped with Surface Mounted Permanents. In Proceeding of the 13th International Workshop Rate-earth Permanent Magnets Application, Birmingham. 1994;151-160.

[7] M.S. Yahaya. Modelling and Control of Active Suspension System using Proportional Integral Sliding Mode Control. Ph.D. Thesis, Universiti Teknologi Malaysia. 2004.

[8] M.S. Yahaya. Robust Control of Active Suspension System for a Quarter Car Model. 2950 Technical Report, Universiti Teknologi Malaysia. 2006.

[9] R. Ankita, Bhise, G.D. Rutuja, R.N. Yerrawar, A.C. Mitra and R. R. Arakerimath. Comparison Between Passive and Semi-Active Suspension System Using Matlab/Simulink. IOSR Journal of Mechanical and Civil Engineering. 2016;13(4):1-6.

[10] I. Martins, J. Esteves, G. D. Marques and F. Pina da Silva. Permanent-magnets Linear Actuators Applicability in Automobile Active Suspensions. IEEE Transactions on Vehicular Technology. 2006;55(1):8694.

[11] B. T. Fijalkowski. Automotive Mechatronics: Operational and Practice Issues, Intelligent Systems. Control and Automation: Science and Engineering 52. 2011.

[12] A.A. Ayman and A.S. Farhan. Vehicle Suspension System Control: A Review. IAENG International Journal of Control, Automation and Systems. 2013; 2(2):46-54.

[13] A. Gokturk. Determination of Appropriate Axial Vibration Dampers for a Naval Vessel Driven by CODAG. Periodicals of Engineering and Natural Sciences. 2017;5(3):371-377.

[14] S. Yaojung, N. Quang-Anh and L. Chun-Chi. A Novel Design of Semi-Active Suspension System Using Magneto Rheological Damper on Light-Weight Vehicle. Transactions of the Canadian Society for Mechanical Engineering. 2013;37(3):723-732.

[15] M.J. Griffin. Handbook of Human Vibration. London: Academic Press. 1996.

[16] A. Shirahatti, P.S.S. Prasad, P. Panzade and M.M. Kulkarni. Optimal Design of Passenger Car Suspension for Ride and Road Holding. Journal of the Brazilian Society of Mechanical Science \& Engineering. 2008; 30(1):66-76.

[17] A. A. A. Zayed, E. Saber, S. F. M. Assal, and A. M. Khourshid. Experimental Investigation of the Effect of Magneto-Rheological MR Damper on a Rotating Unbalance SDOF System. International Journal of Engineering Research \& Technology (IJERT). 2014; 3(12):1082-1092. 
[18] T. Fengchen, Y. Quan, H. Caichun and W. Lida. Experimental Study and Design on Automobile Suspension Made of Magneto-Rheological Damper. International Conference on Future Energy, Environment and Materials. 2012;16: 417-425.

[19] A.B. Mohamed, A. Mansour and A. Farouk. Optimization Study of the Magneto-Rheological Damper for Vehicle Stability and Passenger Comfort. 4th IUGRC International Undergraduate Research Conference, Military Technical College, Cairo, Egypt. July 29-August 1, 2019.

[20] N. Ambhore, S. Hivarale and D. R. Pangavhane. A Study of Bouc-Wen Model of Magnetorheological Fluid Damper for Vibration Control. International Journal of Engineering Research \& Technology (IJERT). 2013; 2(2):1-6.

[21] B. R Spencer, S. J. Dyke, M. K. Sain and J. D. Carlson. Phenomenological Model of a Magnetorheological Damper. Journal of Engineering Mechanics, March 10, 1996:1-23.

[22] C. Fang, B. Y. Zhao, L. S. Chen, Q. Wu, N. Liu, and K. A. Hu. Technical Note: The Effect of The Green Additive Guar Gum on The Properties of Magnetorheological Fluid. Smart Materials and Structures, 2005;14(1).

[23] P. P. Phule and J. M. Ginder. Synthesis and Properties of Novel Magnetorheological Fluids Having Improved Stability and Redispersibility. International Journal of Modern Physics B. 1999;13(14,15\&16):2019-2027.

[24] A. Kruczek and A. Stribrsky. H $\infty$ Control of Automotive Active Suspension with Linear Motor. In Proceedings of the 3rd IFAC Symposium on Mechatronic Systems. 2004;37(14): 365-370.

[25] M. Kusyaie, A. G. A. Muthalif and N. H. Diana. Estimation of Parameter for Different Magnetorheological Fluids Model for Varying Current. IJCEE Computer Electrical Engineering. 2018;10(2):127-134.

[26] K. K. Viswanathan, J. S. Tang, Z.A. Aziz and P. Sambath. Mathematical Modeling of Magneto rheological Fluid Damper in the Semi-Active Suspension System. The 11th National Conference on Mathematical Techniques and Applications. 2019; 2112:020-023.

[27] L. C. Yu. Vibration Control of a Suspension System via a Magnetorheological Fluid Damper. M.S. Thesis, The Chinese University of Hong Kong. 2000.

[28] R. Stanway, J. L. Sproston and N. G. Stevens. NonLinear Modelling of An Electro-Rheological Vibration Damper. Journal of Electrostatics. 1987;20(2):167-184.

[29] S.A. Wahid, I. Ismail, S. Aid and M.S. Rahim. Magneto-Rheological Defects and Failure: A Review. IOP Conference Series: Materials Science and Engineering. 2015;114: 1-12.

[30] L. Balamurugan, J. Jancirani and M. A. Eltantawie. Generalized Magnetorheological (MR) Damper Model and Its Application in Semi-Active Control of Vehicle Suspension System. International Journal of Automotive Technology. 2014;15(3):419-427.
[31] Lord Corporation. Frequently Asked Questions," Lord Corporation. 2003.

[32] S. Sharma. Vibration Control in Quarter-Car Model with Magnetorheological (MR) Dampers Using Bingham Model. Journal of Applied Mechanical Engineering. 2018;7(1):1-5.

[33] J. Gołdasz and B. Sapinski. Insight into Magnetorheological Shock Absorbers. Springer International Publishing, Cham, Switzerland. 2015.

[34] D.R. Gamota and F.E. Filisko. Dynamic Mechanical Studies of Electrorheological Materials. Moderate Frequencies. J. Rheol, 1991;35:399-425.

[35] Z. X. Li, M. Asce and L. H. Xu. Performance Tests and Hysteresis Model of MRF-04K Damper. Journal of Structural Engineering. 2005;131:1303-1306.

[36] G. Yang, B. F. Spencer, J. D. Carlson and M.K. Sain. Large-scale MR fluid dampers: Modeling and dynamic performance considerations. Journal of Structural Engineering. 2002;24:309-323.

[37] D. R. Gamota and F. E. Filisko. Dynamic Mechanical Studies of Electrorheological Materials: Moderate Frequencies. Journal of Rheology. 1991;35:399-425.

[38] R. C. Bell, J.O. Karli, A.N. Vavreck, D.T. Zimmerman, G.T. Ngatu and N.M. Wereley. Magnetorheology of Submicron Diameter İron Microwires Dispersed İn Silicone Oil. Journal of Smart Material and Structural. 2008;17:15-28.

[39] R. Bouc. Mathematical model for hysteresis. Journal of Acustica. 1971;24:16-25.

[40] G.Z. Yao, F.F. Yap, G. Chen, W.H. Li and S.H. Yeo. MR Damper and İts Application for Semi-Active Control of Vehicle Suspension System. Mechatronics 2002;12(7):963-973.

[41] A. Rossi, F. Orsini, A. Scorza, F. Botta, N. P. Belfiore and S. A. Sciuto. A Review on Parametric Dynamic Models of Magnetorheological Dampers and Their Characterization Methods. Actuators. 2018;7.

[42] J. D. Carlson and B. F. Spencer Jr. MagnetoRheological Fluid Dampers for Semi-Active Seismic Control. In Proceedings of the 3rd International Conference on Motion and Vibration Control, Chiba, Japan. 1-6 September 1996.

[43] B. F. Spencer Jr., S. J. Dyke, M.K. Sain and J. D. Carlson. Phenomenological Model for Magnetorheological Damper. Journal of Engineering Mechanical. 1997;123:230-238.

[44] S. J. Dyke Jr., B. F. Spencer, M.K. Sain and J. D. Carlson. Experimental Verification of Semi-active Structural Control Strategies Using Acceleration Feedback. In Proceedings of the 3rd International Conference on Motion and Vibration Control, Chiba, Japan. 1996;3:291-296.

[45] A. Dominguez, R. Sedaghati and I. S. Tiharu. A New Dynamic Hysteresis Model for Magnetorheological Dampers. Smart Material Structural. 2006;15:1179.

[46] L. Pang, G.M Kamath and N.M Wereley. Analysis and Testing of A Linear Stroke Magnetorheological Damper. In Proceedings of the AIAA/ASME/AHS 
Adaptive Structures Forum, Long Beach, CA, USA, CP9803. 1998;2841-2856.

[47] M. H. A. Talib, I. Z. M. Darus and P. M. Samin. Fuzzy Logic With A Novel Advanced Firefly Algorithm and Sensitivity Analysis For Semi-Active Suspension System Using Magneto-Rheological Damper. Journal of Ambient Intelligence and Humanized Computing. 2018; 10:3263-3278.

[48] N. M. Werely, L. Pang and G. M. Kamath. Idealized Hysteresis Modeling of Electrorheological and Magnetorheological Dampers. Journal of Intelligent Material Systems and Structures. 1998;9:642-649.

[49] L. Pang, G. M. Kamath and N. M. Werely. Analysis and Testing of A Linear Stroke Magnetorheological Damper. In Proceedings of the IAA/ASME/AHS Adaptive Structures Forum, Long Beach, CA, USA, CP9803.1998;2841-2856.

[50] R. A. Synder, G. M. Kamath and N. M. Werely. Characterization and Analysis of Magnetorheological Damper Behavior Under Sinusoidal Loading. AIAA Journal. 2001;39:1240-1253.

[51] R. Stanway, J. L. Sproston and A. K. El-Wahed. Applications of Electro-Rheological Fuids In Vibration Control: A Survey. Journal of Smart Material Sructural. 1996;5:464-482.

[52] G. M. Kamath, N. M. Werely and M. R. Jolly. Characterization of Magnetorheological Helicopter Lag Dampers. Journal of American Helicopter Society. 1999;44:234-248.

[53] N. D. Sims, N. J. Holmes and R. Stanway. A Unified Modelling and Model Updating Procedure for Electrorheological and Magnetorheological Dampers. Journal of Smart Material Structural. 2004;13:100-121.

[54] N. D. Sims, D. J. Peel, R. Stanway, A. R. Johnson and W. A. Bullough. The Electrorheological Long-Stroke Damper: A New Modelling Technique With Experimental Validation. Journal of Sound Vibration 2000;229:207-227.

[55] I. Sahin, T. Engin and S. Cesmeci. Comparison of Some Existing Parameter Model for Magnetorheological Fluid Dampers. Journal of Smart Material and Structures. 2010;19:1-11.

[56] F. Meng and J. Zhou. Modeling and Control of a ShearValve Mode MR Damper for Semi-active Vehicle Suspension. Hindawi Mathematical Problems in Engineering, ID 2568185. 2019; 8 pages.

[57] H. Unuh, P. Muhamad, F. Yakub, M. A. Ismail and Z. Tanasta. Experimental Validation to a Prototype Magnetorheological (MR) Semi-Active Damper for CClass Vehicle. International Journal of Automotive and Mechanical Engineering. 2019;16(3):7034-7047.

[58] S.H. Yahaya, S.F. Yaakub, M.S. Salleh, A.R.M. Warikh, A. Abdullah and M.R.A. Purnomo. Mathematical Modelling of the Passive and Semi Active Automobile Suspension Systems in Ford Scorpio Car Model. Journal of Advanced Manufacturing Technology, 13(2):83-96. 